\title{
Myocardial perfusion models: A means or an end?
}

\author{
Nils P. Johnson, MD, MS, ${ }^{\mathrm{a}, \mathrm{b}, \mathrm{c}}$ and K. Lance Gould, $\mathrm{MD}^{\mathrm{a}, \mathrm{b}, \mathrm{c}}$
}

\section{See related article, pp. 64-75}

Why do we model myocardial perfusion? The article by Alessio et $\mathrm{al}^{1}$ in this issue offers a timely opportunity to consider two major, competing reasons. In turn, clarifying the motivations for modeling suggests clear next steps for cardiac positron emission tomography (PET) research.

Fundamentally, the myocardium cares about flow, not pressure. ${ }^{2}$ Therefore, pressure-based fractional flow reserve (FFR) cannot provide a direct measurement of the absolute levels of perfusion and coronary flow reserve (CFR) that produce ischemia., ${ }^{3,4}$ Indeed, the relationship between FFR and CFR, no matter how each is measured, reflects a complex interplay among focal disease, diffuse atherosclerosis, and small vessel dysfunction. ${ }^{5}$ Yet FFR, while not perfect, has strong trial data behind it and remains clearly superior to anatomicguided revascularization. ${ }^{6}$ However, in addition to serving only as a surrogate for flow, FFR requires an invasive procedure. In contrast, quantification of absolute myocardial perfusion and flow reserve by cardiac PET offers a non-invasive alternative and measures flow directly. In short, modeling myocardial perfusion may "build a better mousetrap" for clinicians.

On the other hand, models of perfusion can clarify fundamental physiology. Every model contains assumptions regarding the structure and function of the coronary-myocardial system and also the interaction of the tracer with this system. Each assumption serves as an opportunity to further our understanding. For a system

From the Weatherhead PET Center for Preventing and Reversing Atherosclerosis, ${ }^{\text {a }}$ Division of Cardiology, Department of Medicine,

$\mathrm{b}$ University of Texas Medical School; and Memorial Hermann Hospital, ${ }^{\mathrm{c}}$ Houston, TX.

Reprint requests: K. Lance Gould, MD, Weatherhead PET Center for Preventing and Reversing Atherosclerosis, University of Texas Medical School at Houston, 6431 Fannin St., Room 4.256 MSB, Houston, TX 77030; K.Lance.Gould@uth.tmc.edu.

J Nucl Cardiol 2013;20:20-2.

$1071-3581 / \$ 34.00$

Copyright $@ 2012$ American Society of Nuclear Cardiology.

doi:10.1007/s12350-012-9604-z example, studies of microsphere distribution led prior investigators from the same University of Washington group as the current study to propose a fractal branching structure. ${ }^{7}$ For a tracer example, time-activity curves can study metabolic changes of ammonia after injection. ${ }^{8}$ Perfusion models, therefore, provide an experimental test of existing physiologic theories. In short, modeling myocardial perfusion allows physiologists to "kick the tires" and "look under the hood.",

How well can myocardial perfusion models serve each purpose? Here, both intentions have common ground, namely distinguishing a signal (clinical or physiologic) from background noise. While much effort has been spent on choosing the "best" model to extract the signal of interest, we feel several broad factors have historically been neglected relative to their importance (see Table 1).

First, radionuclide decay has inherent Poisson statistical noise and physical resolution, the former exacerbated by short imaging blocks if using a timeactivity curve method and the latter due to the positron range of tracers. Second, cardiac PET hardware and software introduces distortions due to the point-spread function, reconstruction algorithm, post-processing smoothing filters, and potential nonlinear response of the imaging system. Third, cardiac, respiratory, and abdominal content motion during supine acquisition smears out activity, unlike the perfectly stationary situation in brain PET imaging. Fourth, attenuation correction-regardless if acquired by rotating rod or computed tomography - can suffer from misregistration and in some cases offer an imperfect tradeoff between opposing myocardial segments ${ }^{9}$ or compromise adjacent structures. Fifth, the arterial input necessary for any flow model also suffers from the preceding factors and imaging differences among potential anatomic locations (prior studies have used any combination of thoracic aorta, left atrium, or left ventricular blood pool). ${ }^{10}$

The exact radiotracer and flow model then seek a signal against a background of these five broad categories of noise. Each tracer has its own "physiology" as well. For example, oxygen-15 diffuses freely including into the blood pool, thereby necessitating some type of imaging processing removal, while nitrogen-13 ammonia undergoes a series of complex and time-dependent metabolic changes ${ }^{8}$ that must be taken into consideration. 
Table 1. Broad categories of noise affecting all myocardial perfusion models

\begin{tabular}{|c|c|}
\hline Category & Components \\
\hline $\begin{array}{l}\text { Statistical noise } \\
\text { and physical } \\
\text { resolution }\end{array}$ & $\begin{array}{l}\text { Poisson counting from } \\
\text { radioactive decay } \\
\text { Positron range }\end{array}$ \\
\hline $\begin{array}{l}\text { PET imaging } \\
\text { system }\end{array}$ & $\begin{array}{l}\text { Point-spread function } \\
\text { Reconstruction algorithm } \\
\text { Post-processing smoothing } \\
\text { filters } \\
\text { Non-linear response and } \\
\text { saturation }\end{array}$ \\
\hline Motion & $\begin{array}{l}\text { Cardiac cycle } \\
\text { Respiratory cycle } \\
\text { Settling of abdominal } \\
\text { contents when supine }\end{array}$ \\
\hline $\begin{array}{l}\text { Attenuation } \\
\text { correction }\end{array}$ & $\begin{array}{l}\text { Misregistration } \\
\text { Compromise of adjacent } \\
\text { structures }\end{array}$ \\
\hline Arterial input & $\begin{array}{l}\text { Temporal noise } \\
\text { Various anatomic locations }\end{array}$ \\
\hline
\end{tabular}

Flow models incorporate a range of physiologic sophistication. For example, three compartments (capillary, interstitial, and intracellular spaces) for nitrogen-13 ammonia are often simplified by combining interstitial and intracellular compartments. ${ }^{11}$

With the above context as a foundation, the new work by Alessio et al $^{1}$ can be better understood. Their motivation was primarily physiologic-to replace the more simple assumption of a uniformly homogenous tracer in the two- and three-compartment models with the more realistic assumption that tracer concentration varies along the axial length of each of two compartments (plasma and myocyte). These so-called distributed models may offer more realism, albeit at the price of increased model and computational complexity.

The main finding of interest is that both types of models performed similarly. Their work adds to prior literature that the exact flow model has only marginal importance for clinical decisions. ${ }^{12}$ This result should be comforting for the clinician confronted with an array of potential software packages for estimating absolute flow and CFR by PET. Despite seemingly more realistic physiologic assumptions, the work of Alessio et $\mathrm{al}^{1}$ could not show convincingly superior performance of a distributed model. Specifically, Bland-Altman analysis showed similar results for absolute flow (bias
$0.03 \mathrm{cc} / \mathrm{minute} / \mathrm{g}$ for distributed vs $-0.03 \mathrm{cc} / \mathrm{minute} / \mathrm{g}$ for three compartments, limits of agreement $1.35 \mathrm{cc} /$ minute/g for distributed vs $1.05 \mathrm{cc} / \mathrm{minute} / \mathrm{g}$ for three compartments) and CFR (bias 0.23 for distributed vs -0.16 for three compartments, limits of agreement 1.85 for distributed vs 1.64 for three compartments). Also, absolute blood flow error was similar between assumptions $(0.03 \pm 0.04 \mathrm{cc} / \mathrm{minute} / \mathrm{g}$ for distributed vs $-0.03 \pm 0.03 \mathrm{cc} / \mathrm{minute} / \mathrm{g}$ for three compartments) while CFR error was significantly worse $(0.23 \pm 0.08$ for distributed vs $0.14 \pm 0.07$ for three compartments). While linear slopes were significantly better for absolute blood flow ( 0.98 for distributed vs 0.69 for three compartments) and CFR (0.92 for distributed vs 0.58 for three compartments), correlation coefficients were similar.

However, as their motivation was physiologic, we should ask why their experimental data could not distinguish between assumptions of homogenous tracer concentration and axially distributed tracer concentration. While on the face of it such a result may seem unexpected, it can easily be understood by recalling the five major categories of noise discussed above that limit the raw data used by any PET model of myocardial perfusion. Indeed the authors even write that the "shapes of the model responses to sharp pulse inputs in the two cases are strikingly different, and give different estimates for tracer permeation kinetics, but relatively similar estimates of regional flows. With temporallydispersed inputs and noisy data the distinctiveness of the shapes diminishes." 1 Therefore, the competing physiologic assumptions are too fine to be distinguished based on PET data, even in the idealized setting of a dog model with highly controlled anesthesia, hemodynamics, and conditions of a completely patent versus total coronary occlusion.

As such, the article by Alessio et al $^{1}$ makes clear the next general steps for cardiac PET models of myocardial perfusion. First, their work indirectly emphasizes the importance of the five broad categories of noise that influence any flow model. While some existing literature has already focused on these categories ${ }^{13,14}$ we feel they merit more investigation. Perhaps a sensitivity analysis or Monte Carlo simulations could determine which parameters of the distributed model are most affected, thereby focusing PET equipment and acquisition choices to reduce noise. Second, their work raises the general question of what physiologic insights can be gleaned from cardiac perfusion imaging. Computed tomography and magnetic resonance imaging offer superior spatial resolution and perhaps might better investigate the importance of distributed models. Conversely, cardiac PET offers advantages of metabolic targets, almost no tracer contraindications, improved signal-to-noise if 
integrative models ${ }^{15}$ are used, and coverage of the entire left ventricle with low radiation exposure. The optimal tool should be chosen based on the physiologic question under study.

In conclusion, the dichotomous question in the title of this editorial presents a false choice. Both groupsclinicians and physiologists-model myocardial perfusion but with different goals. For the clinician, such models are just a means to make a treatment decision. For the physiologist, such models are the end result of their mechanistic and structural understanding. Alessio et $\mathrm{al}^{1}$ remind us that both views are valid and important.

\section{References}

1. Alessio AM, Bassingthwaighte JB, Glenny R, Caldwell JH. Validation of an axially-distributed model for quantification of myocardial blood flow using ${ }^{13} \mathrm{~N}$-ammonia PET. J Nucl Cardiol 2012. doi:10.1007/s12350-012-9632-8.

2. Smalling RW, Kelley K, Kirkeeide RL, Fisher DJ. Regional myocardial function is not affected by severe coronary depressurization provided coronary blood flow is maintained. J Am Coll Cardiol 1985;5:948-55

3. Johnson NP, Gould KL. Physiological basis for angina and STsegment change: PET-verified thresholds of quantitative stress myocardial perfusion and coronary flow reserve. JACC Cardiovasc Imaging 2011;4:990-8.

4. Johnson NP, Gould KL. Integrating noninvasive absolute flow, coronary flow reserve, and ischemic thresholds into a comprehensive map of physiological severity. JACC Cardiovasc Imaging 2012;5:430-40.

5. Johnson NP, Kirkeeide RL, Gould KL. Is discordance of coronary flow reserve and fractional flow reserve due to methodology or clinically relevant coronary pathophysiology? JACC Cardiovasc Imaging 2012;5:193-202.
6. Tonino PA, De Bruyne B, Pijls NH, Siebert U, Ikeno F, van't Veer $\mathrm{M}$, et al. Fractional flow reserve versus angiography for guiding percutaneous coronary intervention. N Engl J Med 2009;360:21324.

7. Bassingthwaighte JB, King RB, Roger SA. Fractal nature of regional myocardial blood flow heterogeneity. Circ Res 1989; 65:578-90.

8. Rosenspire KC, Schwaiger M, Mangner TJ, Hutchins GD, Sutorik A, Kuhl DE. Metabolic fate of [13 N]ammonia in human and canine blood. J Nucl Med 1990;31:163-7.

9. Gould KL, Pan T, Loghin C, Johnson NP, Guha A, Sdringola S. Frequent diagnostic errors in cardiac PET/CT due to misregistration of CT attenuation and emission PET images: A definitive analysis of causes, consequences, and corrections. J Nucl Med 2007;48:1112-21

10. Hove JD, Iida H, Kofoed KF, Freiberg J, Holm S, Kelbaek H. Left atrial versus left ventricular input function for quantification of the myocardial blood flow with nitrogen-13 ammonia and positron emission tomography. Eur J Nucl Med Mol Imaging 2004;31:71-6.

11. Coxson PG, Huesman RH, Borland L. Consequences of using a simplified kinetic model for dynamic PET data. J Nucl Med 1997;38:660-7.

12. Slomka PJ, Alexanderson E, Jácome R, Jiménez M, Romero E, Meave A, et al. Comparison of clinical tools for measurements of regional stress and rest myocardial blood flow assessed with $13 \mathrm{~N}$ ammonia PET/CT. J Nucl Med 2012;53:171-81.

13. Coxson PG, Brennan KM, Huesman RH, Lim S, Budinger TF. Variability and reproducibility of rubidium- 82 kinetic parameters in the myocardium of the anesthetized canine. J Nucl Med 1995;36:287-96.

14. Meyer C, Peligrad D-N, Weibrecht M. Assessment of input function distortions on kinetic model parameters in simulated dynamic ${ }^{82} \mathrm{Rb}$ PET perfusion studies. Nucl Instrum Methods Phys Res A 2007;571:199-202.

15. Yoshida K, Mullani N, Gould KL. Coronary flow and flow reserve by PET simplified for clinical applications using rubidium-82 or nitrogen-13-ammonia. J Nucl Med 1996;37:1701-12. 